\title{
Comparison of hemodynamic change following spinal anesthesia in preeclamptic and non- preeclamptic parturients undergoing cesarean section at University of Gondar comprehensive specialized hospital, Northwest Ethiopia.
}

Tikuneh Yetneberk ( $\nabla$ tikusosi@gmail.com )

Debre Tabor university

Yophetah W. Berhe

University of Gondar

Habtamu Getnet

University of Gondar

Mamaru Mollalign

University of Gondar

Research

Keywords: Preeclampsia, Spinal anesthesia, Cesarean section, Hypotension

Posted Date: February 19th, 2020

DOI: https://doi.org/10.21203/rs.2.24012/v1

License: (9) This work is licensed under a Creative Commons Attribution 4.0 International License.

Read Full License

Version of Record: A version of this preprint was published at Patient Safety in Surgery on March 31st, 2020. See the published version at https://doi.org/10.1186/s13037-020-00234-w. 


\section{Abstract}

Background Spinal anesthesia-induced maternal hypotension is the most frequent complication associated with maternal morbidity and mortality during cesarean section. The aim of this study was to compare the incidence and magnitude of hemodynamic changes in preeclamptic and non-preeclamptic parturients undergone cesarean section under spinal anesthesia.

Method A prospective cohort study was conducted from February to May 2019 in University of Gondar comprehensive specialized hospital. A total of 122 ASA II and ASA III parturients were recruited consecutively and assigned to two groups (81non-preeclamptics, and 41 preeclamptics). The data analysis was done by SPSS version 22 statistical software. The data were tested for normality with Shapiro Wilk U-test and normally distributed data were compared by using the independent student's ttest. Whereas non-normally distributed data were compared using the Mann-Whitney U- test. Fisher's exact test was used for intergroup comparison of proportion. All $P$ values $<0.05$ were considered statistically significant.

Result The incidence of spinal anesthesia-induced hypotension was higher in non-preeclamptic parturients than preeclamptic parturients ( $55.6 \%$ vs. $34.1 \%$, respectively) and the degree of blood pressure drop was significantly greater in the non-preeclamptic parturients compared to those with preeclampsia; As well intraoperative fluid consumption was significantly greater in the non-preeclamptics parturients compared to those with preeclamptics.

Conclusion The incidence and magnitude of spinal anesthesia-induced hypotension in parturients undergone cesarean section were less in preeclamptic parturients than in non-preeclamptic parturients. Therefore, don't deny spinal anesthesia for preeclamptic parturients due to fear of profound hypotension, unless there is a contraindication for spinal anesthesia.

\section{Background}

Worldwide preeclampsia/eclampsia is the third leading cause of maternal morbidity and mortality[1]. This is especially the commonest cause of fetomaternal complications in developing countries; around $40-60 \%$ of maternal deaths in these countries are caused by preeclampsia alone; in Ethiopia, $19 \%$ of maternal mortality is caused by hypertensive disorder of pregnancy [2]. The definitive management of preeclampsia is delivery where cesarean section is commonly promoted[3]. A study done in Ethiopia showed that $6.1 \%$ of indications for CS were preeclampsia[4]. There is a paradigm shift in the practice of obstetrics anesthesia from general to spinal anesthesia for cesarean section, but the rate of preventable spinal anesthesia-related deaths is still high[5-7]. Hypotension after spinal anesthesia was the most frequent complication associated with maternal morbidity and mortality during cesarean section[8]. Preeclamptic patients have been considered to be at higher risk of profound hypotension when they undergo cesarean section under spinal anesthesia[9]. 
A study had shown that fluid loading and vasopressor prophylaxis were effective in reducing the incidence of spinal anesthesia-induced hypotension in healthy parturients[11]. But these preemptive measures could put the preeclamptic patients at increased risk of hypertension and pulmonary edema[9]. Due to inconsistent definition, the reported incidence of spinal anesthesia-induced maternal hypotension varies between $7 \%$ and $89.2 \%[10,16]$. Therefore, anesthetic management for preeclamptic parturients who undergo cesarean section is challenging for anesthetists [12]. To alleviate maternal deaths arise from risks attributable to pregnancy and childbirth, the provision of safe anesthesia is necessitating $[3$, $19,24]$.

During obstetric anesthesia, preservation of hemodynamic stability is a big concern for anesthetists[12], especially for preeclamptic parturients who planned to undergo cesarean section [10, 12]. However, spinal anesthesia-induced maternal hypotension is still the most frequent complication [20,21]. Anesthetists denied spinal anesthesia for preeclamptic parturients, due to the fear of profound hypotension and its management crisis (exaggerated response to vasopressor treatment and pulmonary edema following fluid challenges) $[9,12-15]$. Furthermore, the incidence of spinal anesthesia-induced maternal hypotension showed inconsistency across different studies, which makes it almost difficult to set standard targets and develop a local management protocol [20, 21, 33, 34].

\section{Methods And Materials}

A prospective observational cohort study was conducted to determine the incidence of hypotension and the magnitude of hemodynamics change following spinal anesthesia in preeclamptic and nonpreeclamptic parturients undergone cesarean section in University of Gondar comprehensive specialized hospital; Northwest Ethiopia from January to June 2019. ASA II and ASA III parturients were involved in the study. Parturients with cardiac disease, twin pregnancy, total spinal, chronic hypertension, gestational hypertension, superimposed hypertension, renal disease, diabetes mellitus, coagulopathy (platelet count $<80 \times 10^{9} / \mathrm{L}$ ), active labor, eclampsia, abruptio placentae, placenta praevia, any adjuvant added with local anesthetics were excluded. Variables like age, height, BMI, ASA status, gestational age, and amount of fluid preloaded, amount of fluid consumed intraoperatively, the weight of the neonate, upper sensory level of the spinal block at the time of skin incision, position during and after the spinal procedure were studied.

Intraoperative hypotension: Defined as more than $20 \%$ decrease in the mean arterial blood pressure following spinal anesthesia compared to the baseline in both groups [20,21, 25, 33, 34]. Preeclampsia: A pregnancy-induced increase in blood pressure $\geq 140 / 90 \mathrm{mmHg}$ after 20 weeks of gestation and proteinuria $\geq 300 \mathrm{mg} / 24 \mathrm{hrs}[10]$. Preeclampsia with severity feature/severe preeclampsia: Defined as a systolic arterial blood pressure of $160 \mathrm{mmHg}$ or higher, or a diastolic blood pressure of $110 \mathrm{mmHg}$ or higher, associated with proteinuria $>5 \mathrm{~g}$ in 24 hours $[10,35]$. Change in heart rate: When there was a $20 \%$ decrease or increase in heart rate from baseline $[6,10,25,26,36]$. The magnitude of hemodynamics change/severity of hypotension: The percentage falls of blood pressure (SBP, DBP, and MAP) between two measurements and it was calculated as: 
Percentage fall $=$

baseline measurement value-current measurement value

\section{baseline measurement value}

$[10,25,37]$

All consecutive parturients who fulfilled the inclusion criteria and gave birth by cesarean section under spinal anesthesia were included in the study until the intended sample size has been achieved. The sample size was determined based on the latest study done in Macedonia the incidence of hypotension in preeclamptic and non-preeclamptic parturients was $25 \%$ and $53 \%$ respectively [25]and calculated by using the Fleiss correction factor method with a power of $80 \%$ at a $5 \%$ significance level and the sample size was 122. Hereafter, 41 participants were enrolled in the preeclamptic group and 81 participants were enrolled in non-preeclamptic groups with a proportion of 1:2 ratios respectively. All parturients who satisfy the inclusion criteria were included in the study period. There was homogeneity of variance, as assessed by Levene's test for equality of variances.

In the operation theater, baseline hemodynamic variables (SBP, DBP, MAP, and HR) were recorded. Baseline BP was taken as the mean of the two readings measured one minute apart and five minutes after the parturient arrived in the operation theatre and before doing any invasive procedures. After spinal anesthesia SBP, DBP, MAP, and HR were recorded every 2 minutes for 30 minutes and every 5 minutes thereafter until the end of surgery. Patients were monitored with non-invasive automated blood pressure cuffs, ECG, and pulse oximetry. The data collectors have assessed the upper level of sensory block bilaterally by pinprick at the time of skin incision and it was documented. The total intraoperative fluid consumption, total estimated blood loss, the weight of the newborn were documented as well. The data collection technique was a combination of chart review, observation, and interview using a pre-tested questioner that was developed in English language.

After completion of the data collection, the data was entered into Epidata version 4.2. Software and exported to SPSS version 22 statistical software for further analysis. The data were tested for normality with Shapiro Wilk U-test and normally distributed data were compared by using the independent student's t-test and expressed as mean $\pm S D$. Whereas non-normally distributed data were compared using the Mann-Whitney U- test and expressed as medians(IQR). Fisher's exact test was used for intergroup comparisons of proportion. All $P$ values $<0.05$ were considered significant. The research was taken ethical clearance from University of Gondar College of medicine and health science ethical review board and written informed consent was taken from each study participants.

\section{Results}

A total of 122 parturients were enrolled (81 non-preeclamptic and 41 preeclamptic parturients) in this study. There were no statistically significant differences in socio-demographic and anesthetic characteristics of parturients such as; age, weight, height, the volume of $0.5 \%$ plain bupivacaine, and 
speed of spinal administration between groups (Tables 1 and 3). The majority of preeclamptic parturients were ASA II and the remains were ASA III, while, All parturients in the non-preeclamptic group were ASA II, and this difference was statistically significant between groups; $p<0.001$ (Table 1). The mean gestational age at the time of cesarean section was significantly lower in the preeclamptic group: $38.56 \pm 1.63$ weeks in non-preeclamptic versus $37.44 \pm 1.25$ weeks in preeclamptics; $p=0.001$ (Table 1 ). However, there was no significant difference in the mean weight of the newborn between groups; $p=0.37$ ([Table 1 ).

Table 1

Maternal and neonatal characteristics, University of Gondar Northwest Ethiopia, May 2019(n=122)

\begin{tabular}{|c|c|c|c|}
\hline Variable & non-preeclampsia $(n=81)$ & Preeclampsia $(n=41)$ & p-value \\
\hline Age(year)* & $27.93 \pm 3.60$ & $27.95 \pm 3.99$ & 0.972 \\
\hline Weight $(\mathrm{kg})^{\star}$ & $64.72 \pm 7.82$ & $65.95 \pm 7.65$ & 0.408 \\
\hline Height $(\mathrm{cm})^{*}$ & $162.47 \pm 6.29$ & $164.10 \pm 5.83$ & 0.169 \\
\hline $\begin{array}{l}\text { BMI }\left(\mathrm{kg} / \mathrm{m}^{2}\right)^{\star} \\
\text { ASA status n (\%) } \\
\text { ASA II } \\
\text { ASA III } \\
\text { Nulliparous n (\%) }\end{array}$ & $\begin{array}{l}24.63 \pm 3.57 \\
81(100) \\
33(40.7)\end{array}$ & $\begin{array}{l}24.57 \pm 3.18 \\
28(68.3) \\
13(31.7) \\
21(51.2)\end{array}$ & $\begin{array}{l}0.927 \\
<0.001 \\
0.335\end{array}$ \\
\hline $\begin{array}{l}\text { Gestational age(week)* } \\
\text { weight of the new born }(\mathrm{kg})^{\star} \\
\text { Previous cesearn section } \mathrm{n}(\%) \\
\text { Yes } \\
\text { No }\end{array}$ & $\begin{array}{l}38.56 \pm 1.63 \\
3.03 \pm 0.42 \\
26(32.1) \\
55(67.9)\end{array}$ & $\begin{array}{l}37.44 \pm 1.25 \\
2.96 \pm 0.40 \\
9(22) \\
32(78)\end{array}$ & $\begin{array}{l}0.001 \\
0.374 \\
0.293\end{array}$ \\
\hline
\end{tabular}


Table 3

Anesthetic characteristics and procedural position of parturients; University of Gondar Northwest Ethiopia, May 2019 $(n=122)$

\begin{tabular}{|c|c|c|c|}
\hline Variable & $\begin{array}{l}\text { Non-preeclamptic ( } \mathrm{n} \\
=81 \text { ) }\end{array}$ & $\begin{array}{l}\text { Preeclamptic(n } \\
=41)\end{array}$ & $\begin{array}{l}\mathrm{p}- \\
\text { value }\end{array}$ \\
\hline Volume of injected bupivacaine $(\mathrm{ml})^{\star}$ & $2.30 \pm 0.25$ & $2.27 \pm 0.25$ & 0.558 \\
\hline Dose of $0.5 \%$ plain bupivacaine $(\mathrm{mg}) *$ & $11.48 \pm 1.24$ & $11.34 \pm 1.26$ & 0.558 \\
\hline Speed of spinal administration $(\mathrm{ml} / \mathrm{sec})^{*}$ & $0.18 \pm 0.12$ & $0.21 \pm 0.08$ & 0.323 \\
\hline Upper sensory level** & T6(T4-T6) & T5(T4-T6) & 0.032 \\
\hline $\begin{array}{l}\text { Position during spinal procedure } \mathrm{n}(\%) \\
\text { Sitting } \\
\text { Lateral }\end{array}$ & $\begin{array}{l}80(98.8) \\
1(1.2)\end{array}$ & $\begin{array}{l}39(95.1) \\
2(4.9)\end{array}$ & 0.223 \\
\hline $\begin{array}{l}\text { Position after spinal procedure } \mathrm{n}(\%) \\
\text { Supine } \\
\text { Left Lateral tilt } \\
\text { Parturients treated with adrenaline } \\
\text { intraoperatively } \mathrm{n}(\%) \\
\text { Yes } \\
\text { No }\end{array}$ & $\begin{array}{l}80(98.8) \\
1(1.2) \\
2(2.5) \\
79(97.5)\end{array}$ & $\begin{array}{l}41(100) \\
41(100)\end{array}$ & $\begin{array}{l}0.479 \\
0.550\end{array}$ \\
\hline
\end{tabular}

The median upper sensory level at the time of skin incision was higher in the preeclamptic parturients compared to those with non-preeclamptics and this difference was statistically significant (T5 vs. T6; $p=$ 0.032) (Table 3). The baseline SBP, DBP, MAP, and heart rate were higher in parturients with preeclampsia than the corresponding values among the non-preeclamptic parturients (Table 2). Non-preeclamptic parturients have been taken a higher volume of preload fluid compared with preeclamptics $(611.67 \mathrm{ml} \pm$ $289.65 \mathrm{VS} 565.44 \mathrm{ml} \pm 318.45 ; \mathrm{p}=0.004$ ) (Table 4) and there was a statistically significant difference in intraoperative intravenous fluid consumption between groups, which was higher in non-preeclamptics compared to preeclamptic parturients $(1723.46 \mathrm{ml} \pm 352.41 \mathrm{vs} 1463.41 \pm 417.59 ; \mathrm{p}=0.001)$ (Table 4$)$. The mean duration of surgery was comparable between the two groups (Table 4). 
Table 2

Baseline hemodynamic characteristic of the parturients, University of Gondar Northwest Ethiopia, May $2019(n=122)$

\begin{tabular}{|llll|}
\hline Variable & non-preeclampsia( $\mathbf{n = 8 1})$ & Preeclampsia(n= 41) & p-value \\
\hline Baseline SBP $(\mathrm{mmHg})$ & $118.83 \pm 9.22$ & $134.95 \pm 11.71$ & 0.001 \\
\hline Baseline DBP $(\mathrm{mmHg})$ & $75.52 \pm 8.64$ & $85.90 \pm 10.40$ & 0.001 \\
\hline Baseline MAP $(\mathrm{mmHg})$ & $83.20 \pm 8.45$ & $85.32 \pm 10.24$ & 0.218 \\
\hline Baseline heart rate(beats/minute) & $95.95 \pm 15.79$ & $99.38 \pm 20.21$ & 0.321 \\
\hline $\begin{array}{l}\text { Independent student t-test. SBP = systolic blood pressure, DBP = diastolic blood pressure, MAP = mean } \\
\text { arterial pressure, } \mathrm{mmHg}=\text { millimeter mercury. }\end{array}$ & \\
\hline
\end{tabular}

Table 4

Fluid consumption, estimated blood loss and surgical conditions, University of Gondar Northwest Ethiopia, May 2019 $(n=122)$

\begin{tabular}{|c|c|c|c|}
\hline Variable & non-preeclampsia $(\mathrm{n}=81)$ & Preeclampsia(n = 41) & p-value \\
\hline $\begin{array}{l}\text { crystalloid preload(ml) } \\
\text { Intraoperative IV fluid(ml) }\end{array}$ & $\begin{array}{l}611.67 \pm 289.65 \\
1723.46 \pm 352.41\end{array}$ & $\begin{array}{l}565.44 \pm 318.45 \\
1463.41 \pm 417.59\end{array}$ & $\begin{array}{l}0.004 \\
0.001\end{array}$ \\
\hline Estimated blood loss(ml) & $382.96 \pm 134.12$ & $379.02 \pm 132.74$ & 0.878 \\
\hline Duration of surgery(minute) & $43.89 \pm 11.75$ & $42.68 \pm 9.16$ & 0.567 \\
\hline Experience of obstetrician(year) & $2.93 \pm 0.67$ & $3.00 \pm 0.84$ & 0.596 \\
\hline Experience of anesthetist(year) & $3.42 \pm 1.39$ & $3.71 \pm 1.27$ & 0.268 \\
\hline
\end{tabular}

In the preeclamptic parturients, mean SBP and DBP were higher than the corresponding values among non-preeclamptic parturients following spinal anesthesia at each point of time (Fig. 3, 4) and the same fashion was happening to MAP, which was at a higher level in preeclamptic parturients than nonpreeclamptic parturients (Fig. 2). The incidence of hypotension in non-preeclamptic parturients $(55.6 \%)$ was higher than that of preeclamptic parturients (34.1\%) (Table 5), despite the former receiving much volume of intravenous fluid ( $1723.46 \mathrm{ml} \pm 352.41$ versus $1463.41 \mathrm{ml} \pm 417.59 ; \mathrm{p}=0.001$ ) (Table 4). There was also a decrease in blood pressure after spinal anesthesia in both groups, but the magnitude of blood pressure falls were significantly greater in the non-preeclamptic parturients compared to those with preeclampsia: $27.78 \% \pm 5.44$ vs. $21.05 \% \pm 3.06$ for SBP, $26.18 \% \pm 4.07$ vs. $23.93 \% \pm 4.79$ for DBP, and $25.65 \% \pm 2.22$ vs. $21.27 \% \pm 15.15$ for $\operatorname{MAP}(p<0.001)$ (Table 5$)$. 
Table 5

Incidence and magnitude of hemodynamic changes following spinal anesthesia, University of Gondar Northwest Ethiopia, May 2019( $\mathrm{n}=122)$

\begin{tabular}{|c|c|c|c|}
\hline Variable & Non-preeclampsia( $(n=81)$ & Preeclampsia(n = 41) & p-value \\
\hline $\begin{array}{l}\text { Incidence of hypotension } \mathrm{n}(\%) \# \\
\text { Lowest SBP after SA(mmHg) }\end{array}$ & $\begin{array}{l}45(55.6) \\
85.5 \pm 2.12\end{array}$ & $\begin{array}{l}14(34.1) \\
106.80 \pm 12.17\end{array}$ & 0.035 \\
\hline Decrease from baseline \%* & $27.78 \pm 5.44$ & $21.05 \pm 3.06$ & $<0.001$ \\
\hline lowest DBP after SA(mmHg) & $56 \pm 8.55$ & $65 \pm 5$ & \\
\hline Decrease from baseline \%* & $26.18 \pm 4.07$ & $23.93 \pm 4.79$ & $<0.001$ \\
\hline lowest MAP after $\mathrm{SA}(\mathrm{mmHg})$ & $61.99 \pm 7.59$ & $65 \pm 0.00$ & \\
\hline $\begin{array}{l}\text { A decrease from baseline \%* } \\
\text { Mean HR after SA (beats/minute)* } \\
20 \% \text { decrease in HR } n(\%) \\
20 \% \text { increase in HR } n(\%)\end{array}$ & $\begin{array}{l}25.65 \pm 2.22 \\
90.40 \pm 9.96 \\
72(88.9) \\
2(2.5)\end{array}$ & $\begin{array}{l}21.27 \pm 15.15 \\
89.21 \pm 12.33 \\
31(75.6)\end{array}$ & $\begin{array}{l}<0.001 \\
0.567 \\
0.068 \\
0.550\end{array}$ \\
\hline \multicolumn{4}{|c|}{$\begin{array}{l}\text { *Independent student } t \text {-test. } \# \text { Fisher's exact test. } n=\text { number, } S A=\text { spinal anesthesia, } S B P=\text { systolic } \\
\text { blood pressure, } \mathrm{DBP}=\text { diastolic blood pressure, } M A P=\text { mean arterial pressure, } \mathrm{HR}=\text { heart rate, } \mathrm{mmHg} \\
=\text { millimeter mercury. }\end{array}$} \\
\hline
\end{tabular}

\section{Discussion}

During cesarean section, hypotension following spinal anesthesia was the commonest complication related to maternal morbidity and mortality $[6,8,25]$. Because of inconsistent definitions, the reported incidence of hypotension after spinal anesthesia in cesarean section varies between $7 \%$ and $89.2 \%[6,8$, $10,11,16]$. There was a widespread belief that preeclamptic parturients were considered at higher risk of profound hypotension following spinal anesthesia $[10,12,25,38]$. This concern may often frighten anesthetists from choosing spinal anesthesia for cesarean section in preeclamptic parturients $[10,12$, 25].

Nikooseresht $\mathrm{M}$ et al. found that SBP, DBP, and MAP measured at the baseline were higher for the patients with preeclampsia, and the lowest mean SBP, DBP, and MAP measured among the preeclamptic patients were higher than the corresponding values among the healthy parturients[10]. This finding was in line with our study result. In this study, the incidence of hypotension after spinal anesthesia in preeclamptic parturients $(34.1 \%)$ was less than that of non-preeclamptic parturients $(55.6 \%)(p=0.035)$. This discrepancy in the incidence of hypotension related to preeclampsia related factors. Despite the sympathetic block due to spinal anesthesia, because of exaggerated vasoconstriction, preeclamptic parturients can still maintain their vascular tone that caused only a limited decrease in blood pressure.

Following spinal anesthesia, the mean SBP, DBP, and MAP measured at different time points were higher in preeclamptic parturients than the corresponding values among non-preeclamptic parturients. But this 
difference was insignificant between groups at 14, 18,22, 24, 26,35minutes in SBP, at 8 and 40minutes in DBP, at $10,14,24,35$ minutes in MAP, and thereafter to the end of surgery. Whereas, the mean pulse rate was comparable between groups at different time points after SA. Mitra $\mathrm{M}$ et al. found significant differences in SBP, DBP, and MAP at each point of time in both groups[37]. The possible explanation for this discrepancy might be the employment of invasive blood pressure monitoring in their study, in contrast to our study.

Similar to our study Aya AG et al. found that severely preeclamptic patients had a less frequent incidence of clinically significant hypotension compared to healthy parturients $(16.6 \%$ versus $53.3 \% ; P=0.006[39]$. The incidence of hypotension among preeclamptic parturients in our study was higher than Aya AG et al. result. The likely reason may be the use of different criteria for defining hypotension ( $20 \%$ versus $30 \%$ decline to baseline MAP) and the use of the small volume of preload in our study participants compared to Aya AG et al. $(565.38 \mathrm{ml} \pm 318.4 \mathrm{vs} 1653 \mathrm{ml} \pm 331)$.

In contradict to our result, Mendes et al. found that there was no statistically significant difference regarding the occurrence of hypotension after spinal anesthesia between severely preeclamptic and healthy parturients. But the incidence rate of hypotension was high in both groups $(84 \%$ and $70 \%, p=0.45)$ [26]. This difference may be due to the intraoperative administration of intravenous hydralazine in preeclamptic parturients in their study.

Sivevski A et al. found that the percentage of fall of BP from baseline were significantly greater in the healthy parturients compared to those with preeclampsia $(25.8 \% \pm 10.1$ vs. $18.8 \% \pm 17.0$ for SBP, $28.5 \% \pm$ 8.8 vs. $22.5 \% \pm 10.4$ for $D B P$, and $31.2 \% \pm 14.2$ vs. $18.2 \% \pm 12.6 \%$ for MAP, $p<0.05$ [25]. Likewise, another study conducted by Saha $D$ et al. found that the percentage of fall of DBP and MAP calculated from the baseline was also less in the preeclamptic group (34.5\% and $33 \%$ in normotensive as opposed to $30.3 \%$ and $32.3 \%$ in preeclamptics, respectively)[1]. The result of our study was in accordance with the above findings.

Unlike our study, Mendes et al. found that there was no significant difference in the lowest mean drop of SBP and DBP after spinal anesthesia between preeclamptic and healthy parturients[26]. This difference may be due to standardized fluid management and administration of potent direct vasodilator during surgery (intravenous hydralazine) in preeclamptic parturients in their study. In this study, a decreasing dose of $0.5 \%$ bupivacaine was practiced for the cesarean section. However, the incidence of hemodynamic change had not a significant difference $(10 \mathrm{mg}$ versus $12.5 \mathrm{mg})$. This finding was corresponding with a study done by Moshiri E et al. [40]. The result of our study showed that the mean gestational age in parturients with preeclampsia was considerably different compared with those of the non-preeclamptic parturients. This finding was in line with a study done by Sivevski A et al. [25].

Comparable to Sivevski A et al. finding [25], the result of our study showed that there was a statistically significant difference regarding the volume of preload taken between groups, which was higher in nonpreeclamptic parturients compared to preeclamptic parturients $(611.67 \mathrm{ml} \pm 289.65 \mathrm{VS} 565.44 \mathrm{ml} \pm$ $318.45 ; p=0.004)$. In our study, intraoperative fluid consumption was lower in preeclamptic parturients 
compared with non-preeclamptic parturients $(1463.41 \pm 417.59 \mathrm{VS} 1723.46 \mathrm{ml} \pm 352.41 ; \mathrm{p}=0.001)$. This result was in line with Nikooseresht $M$ et al.[10]. Similar to a study done by Lavie A et al.[36], in our study, the total estimated blood loss was comparable between groups, and no blood products were required throughout the procedure. Nikooseresht $\mathrm{M}$ et al. also found that the surgical durations were comparable between two groups[10]. This finding was in line with our study result.

In our study measurement of vasopressor consumption was difficult, due to the absence of standardized vasopressor usage in the hospital. Anesthetists were trying to manage hypotension with fluids and adrenaline accordingly. In this study, two parturients in the non-preeclamptic group were treated with adrenaline but there were no parturients treated with adrenaline in the preeclamptic groups. However, this difference was not statistically significant $(p=0.550)$. Even though our study does not quantify it, studies found that hypotension requiring vasopressor medication(ephedrine and phenylephrine) following spinal anesthesia was less common in parturients with preeclampsia than in non-preeclamptic parturients[12, $17,25,37,38,41,42]$. The limitation of this study was the small sample size, observational study design which was difficult to control all possible co-founders(like oxytocin), and inability to quantify vasopressor consumption; due to lack of standardized vasopressor(ephedrine and phenylephrine)usage in the practice, which could affect the trends of hemodynamic change over time. As well the use of noninvasive blood pressure measurement in this study might miss some data which can be noticed in invasive blood pressure measurement

Conclusion: This study showed that the incidence and magnitude of spinal anesthesia-induced hypotension in parturients undergone cesarean section were less in preeclamptics than in nonpreeclamptic parturients. In the preeclamptics group, they also experienced spinal anesthesia-induced hypotension, but the incidence and degree of hypotension were significantly lower than non-preeclamptic parturients.

\section{Abbreviations}

ASA American Society of Anesthesiologists

BMI Body Mass Index

BP Blood Pressure

CS Cesarean Section

DBP Diastolic Blood Pressure

GA General Anesthesia

MAP Mean Arterial Pressure

SA Spinal Anesthesia 


\section{Declarations}

\section{Ethics declarations}

\section{Ethical approval and consent to participate}

In order to keep the ethical soundness of the research, an ethical approval letter was obtained from the Institutional Review Board (IRB) of University of Gondar College of medicine and health sciences. Verbal and written consent was also secured before data collection.

\section{Consent for publication}

Not applicable.

\section{Availability of data and materials}

All data generated or analysed during this study are included in this published article

\section{Funding}

The entire funding to conduct this study was provided by University of Gondar College of Medicine and health science, Gondar, Ethiopia.

\section{Competing interests}

The authors declare that they have no competing interests.

\section{Contributions}

TY initiated the idea, carried out the study, and involved in drafting the manuscript. YW contributed to the statistical analysis and in preparing the manuscript. TY and HG contributed to the entry, analysis, critically revised the paper and provided the final version. MM edits starting from the proposal development up to the final manuscript writing and critically reviewed the manuscript for intellectual content. All authors read and approved the final manuscript.

\section{Acknowledgment}


We would like to give our thanks to university of Gondar college of medicine and health science for funding the research project and our heartfelt gratitude also extends to data collectors and respected study participants

\section{References}

1. Saha $D$, et al. Comparison of hemodynamic response and vasopressor requirement following spinal anesthesia between normotensive and severe preeclamptic women undergoing caesarean section: A prospective study. Journal of Obstetric Anaesthesia and Critical Care. 2013;3(1):23.

2. Ankichetty SP,et al. Regional anesthesia in patients with pregnancy-induced hypertension. Journal of anaesthesiology, clinical pharmacology. 2013;29(4):435.

3. Sobhy S, et al. Type of obstetric anesthesia administered and complications in women with preeclampsia in low-and middle-income countries: A systematic review. Hypertension in pregnancy. 2017;36(4):326-36.

4. Abebe FE, et al. Factors leading to cesarean section delivery at Felegehiwot referral hospital, Northwest Ethiopia: a retrospective record review. Reproductive health. 2015;13(1):6.

5. Gibbs M, et al. Managing spinal hypotension during caesarean section: An update. South African Medical Journal. 2018;108(6):460-3.

6. Bishop D, et al. Obstetric spinal hypotension: Preoperative risk factors and the development of a preliminary risk score-the PRAM score. South African Medical Journal. 2017;107(12):1127-31.

7. Anaesthesiologists 0 . The management of high spinal anesthesia in obstetrics: Suggested clinical guidelines in the South African context. Southern African Journal of Anaesthesia and Analgesia. 2016;22(1 Supplement 1): S1-S5.

8. Zwane S, et al. Hypotension during spinal anesthesia for Caesarean section in a resource-limited setting: towards a consensus definition. Southern African Journal of Anaesthesia and Analgesia. 2019;25(1):1-5.

9. Chattopadhyay $S$, et al. Fetomaternal outcome in severely preeclamptic women undergoing emergency cesarean section under either general or spinal anesthesia. Journal of pregnancy. 2014;2014.

10. Nikooseresht $\mathrm{M}$, et al. Comparing the hemodynamic effects of spinal anesthesia in preeclamptic and healthy parturients during cesarean section. Anesthesiology and pain medicine. 2016;6(3).

11. Lee JE, et al. Spinal-induced hypotension: Incidence, mechanisms, prophylaxis, and management: Summarizing 20 years of research. Best Practice \& Research Clinical Anaesthesiology. 2017;31(1):57-68.

12. Dennis A, et al. Management of pre-eclampsia: issues for anesthetists. Anesthesia. 2012;67(9):100920.

13. Aya AG, et al. Spinal anesthesia-induced hypotension: a risk comparison between patients with severe preeclampsia and healthy women undergoing preterm cesarean delivery. Anesthesia \& 
Analgesia. 2005;101(3):869-75.

14. Ramadan TM, et al. Fetomaternal Outcome in Severe Preeclamptic Women Undergoing Emergency Cesarean Section with Spinal or General Anesthesia. Egyptian Journal of Hospital Medicine (July 2018). 2018;72(6):4596-601.

15. Başaran B, et al. Anesthetic practices for patients with preeclampsia or HELLP syndrome: A survey. Journal of the Turkish German Gynecological Association. 2016;17(3):128.

16. Agegnehu A, et al. Effectiveness of Intravenous Prophylactic Phenylephrine for the Prevention of Spinal Anaesthesia Induced Hypotension during Caesarean Section. A Prospective Observational Study. J Anesth Clin Res. 2017;8(779):2.

17. Chaudhary $S$, et al. Subarachnoid block for caesarean section in severe preeclampsia. Journal of anaesthesiology, clinical pharmacology. 2011;27(2):169.

18. Berhe AK, et al. Prevalence of hypertensive disorders of pregnancy in Ethiopia: a systemic review and meta-analysis. BMC pregnancy and childbirth. 2018;18(1):34.

19. Say L, et al. Global causes of maternal death: a WHO systematic analysis. The Lancet Global Health. 2014;2(6):e323-e33.

20. Lee JE, et al. Spinal-induced hypotension: Incidence, mechanisms, prophylaxis, and management: Summarizing 20 years of research. Best Pract Res Clin Anaesthesiol. 2017;31(1):57-68.

21. Chooi $\mathrm{C}$, et al. Techniques for preventing hypotension during spinal anesthesia for caesarean section. The Cochrane database of systematic reviews. 2017;8:Cd002251.

22. Duley L, editor The global impact of pre-eclampsia and eclampsia. Seminars in perinatology; 2009: Elsevier.

23. Sivevski AG, et al. Comparison of low dose spinal anesthesia with general anesthesia in preeclamptic parturients undergoing emergency cesarean section. Anaesthesia, Pain \& Intensive Care. 2015;19(1).

24. Epiu I, et al. Challenges of anesthesia in low-and middle-income countries: a cross-sectional survey of access to safe obstetric anesthesia in East Africa. Anesthesia and analgesia. 2017;124(1):290.

25. Sivevski A, et al. Spinal-Induced Hypotension in Preeclamptic and Healthy Parturients Undergoing Cesarean Section. Open access Macedonian journal of medical sciences. 2019;7(6):996-1000.

26. Mendes $F$, et al. Hemodynamic effects of spinal anesthesia for cesarean section are equivalent in severely preeclamptic and healthy parturients. J Anesthe Clinic Re. 2011.

27. Dusitkasem S, et al. Comparison of Phenylephrine and Ephedrine in Treatment of Spinal-Induced Hypotension in High-Risk Pregnancies: A Narrative Review. Frontiers in medicine. 2017;4:2.

28. Mohta $\mathrm{M}$, et al. Randomised double-blind comparison of bolus phenylephrine or ephedrine for treatment of hypotension in women with pre-eclampsia undergoing caesarean section. Anesthesia. 2018.

29. Fakherpour A, et al. Maternal and anesthesia-related risk factors and incidence of spinal anesthesiainduced hypotension in elective caesarean section: A multinomial logistic regression. Indian journal 
of anesthesia. 2018;62(1):36.

30. Hasanin A, et al. Hemodynamic effects of lateral tilt before and after spinal anesthesia during cesarean delivery: an observational study. BMC anesthesiology. 2018;18(1):8.

31. Bishop D, et al. Heart rate variability as a predictor of hypotension following spinal for elective caesarean section: a prospective observational study. Anesthesia. 2017;72(5):603-8.

32. Khatri RK, et al. Perioperative hemodynamic response and vasopressor requirement during spinal anesthesia for cesarean section in healthy and severe preeclamptic parturients: a prospective cohort comparison. Anaesthesia, Pain \& Intensive Care. 2019:152-6.

33. Klöhr S, et al. Defınitions of hypotension after spinal anesthesia for caesarean section: literature search and application to parturients. Acta anaesthesiologica Scandinavica. 2010;54(8):909-21.

34. Mitra JK, Roy J, et al. Changing trends in the management of hypotension following spinal anesthesia in cesarean section. Journal of postgraduate medicine. 2013;59(2):121-6.

35. Gynecologists Acooa. Task force on hypertension in pregnancy. Obstet Gynecol. 2013;122:1122.

36. Lavie A, et al. Maternal cardiovascular hemodynamics in normotensive versus preeclamptic pregnancies: a prospective longitudinal study using a noninvasive cardiac system (nicas ${ }^{\mathrm{TM}}$ ). BMC pregnancy and childbirth. 2018;18(1):229.

37. Mitra M, et al. Comparison of the Hemodynamic Alterations in Normotensive and Preeclamptic Pregnant Woman Posted for Cesarean Section under Subarachnoid Block. J Cardiovasc Dis Diagn. 2016;4(242):2.

38. Brichant JF, et al. Preeclampsia: an update. Acta anaesthesiologica Belgica. 2014;65(4):137-49.

39. Gutsche BB, et al. Patients with Severe Preeclampsia Experience Less Hypotension during Spinal Anesthesia for Elective Cesarean Delivery Than Healthy Parturients: A Prospective Cohort Comparison. Survey of Anesthesiology. 2004;48(3):127-8.

40. Moshiri E, et al. Comparison of Spinal Anesthesia With Low and Conventional Doses of Bupivacaine on Hemodynamic Changes in Severe Preeclampsia Patients Candidate for Cesarean Section. Biomedical and Pharmacology Journal. 2017;10(2):627-32.

41. Kee WDN, et al. The use of vasopressors during spinal anesthesia for caesarean section. Current Opinion in Anesthesiology. 2017;30(3):319-25.

42. Deshpande AV, et al. Spinal anesthesia in preeclamptic parturients. Journal of Evolution of Medical and Dental Sciences. 2014;3(8):1915-20.

\section{Figures}


Figure 1 not available in this version

\section{Figure 1}

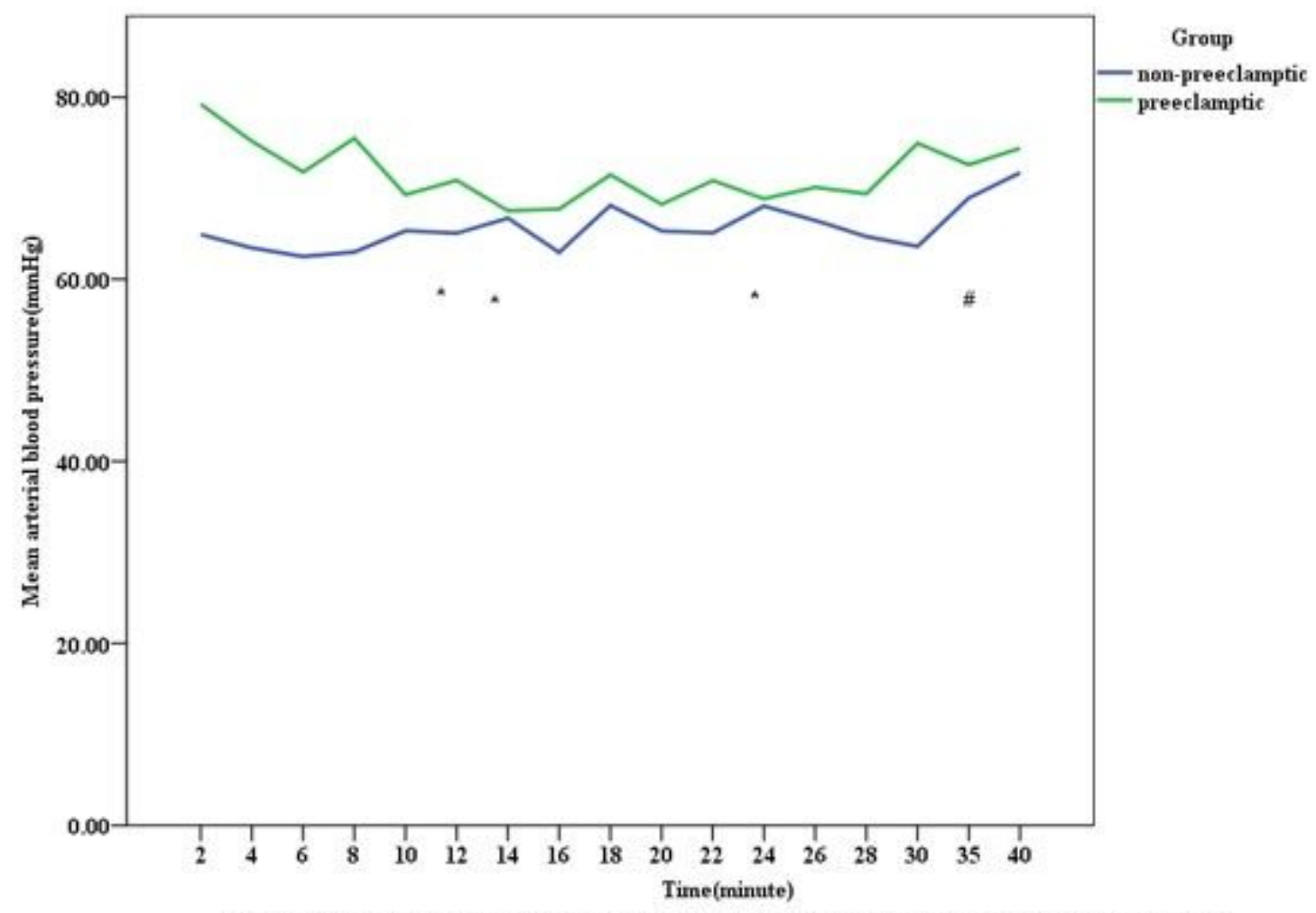

"time points at which there were insignifiant difference in mean arterial blood pressure between groups

\# time points thereafter to the end of surgery there were insignificant difference in mean arterial blood pressure between groups

\section{Figure 2}

Trends of mean arterial blood pressure change following spinal anesthesia in non-preeclamptic and preeclamptic parturients, University of Gondar Northwest Ethiopia, May 2019(n=122). 


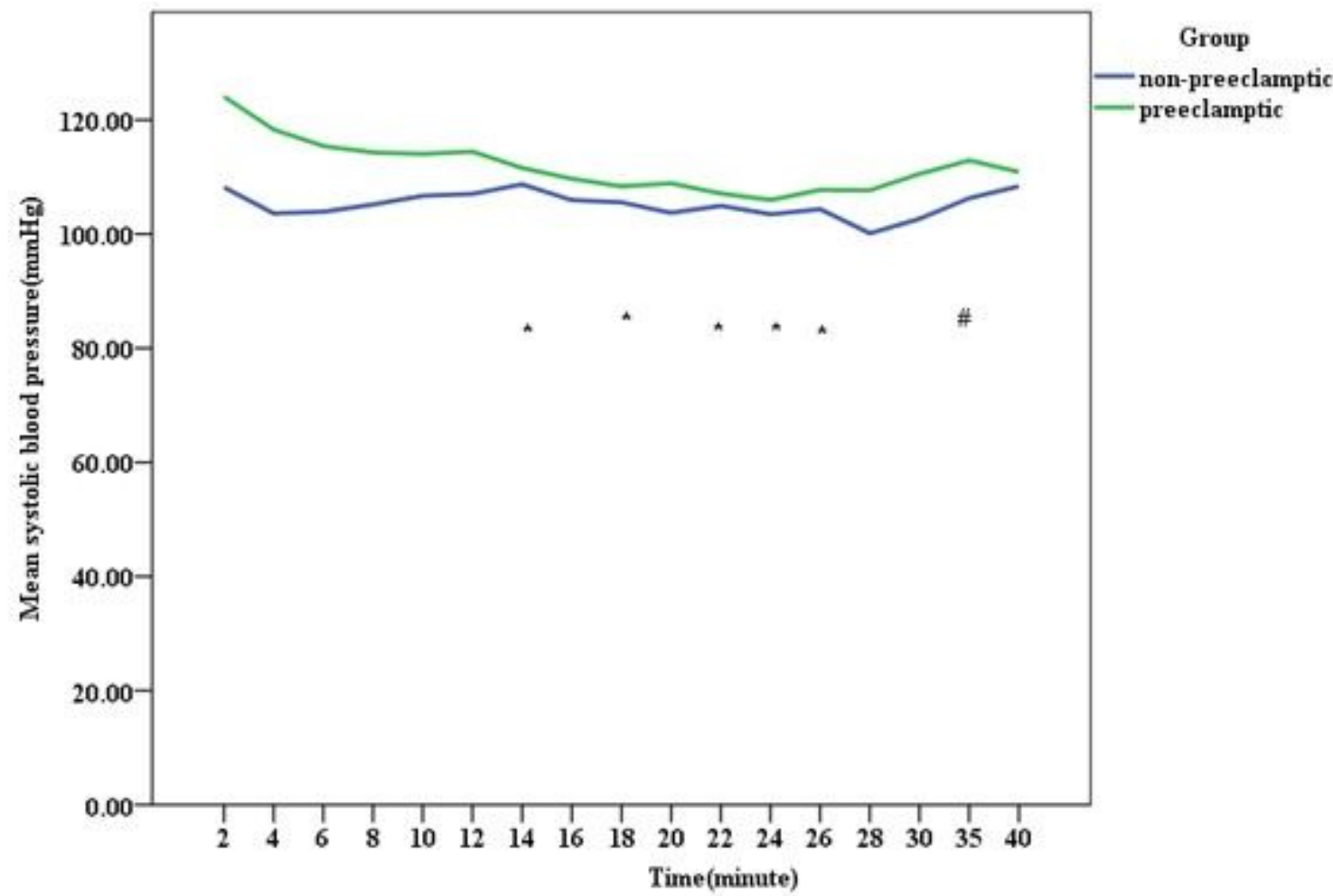

${ }^{*}$ time ponits at which there were insignificant diffierence in mean systolic blood pressure between groups

\# time points thereafter to the end of surgery there were insignificant difference in mean SBP between groups

\section{Figure 3}

Trends of systolic blood pressure change following spinal anesthesia in non-preeclamptic and preeclamptic parturients, University of Gondar Northwest Ethiopia, May 2019(n=122). 


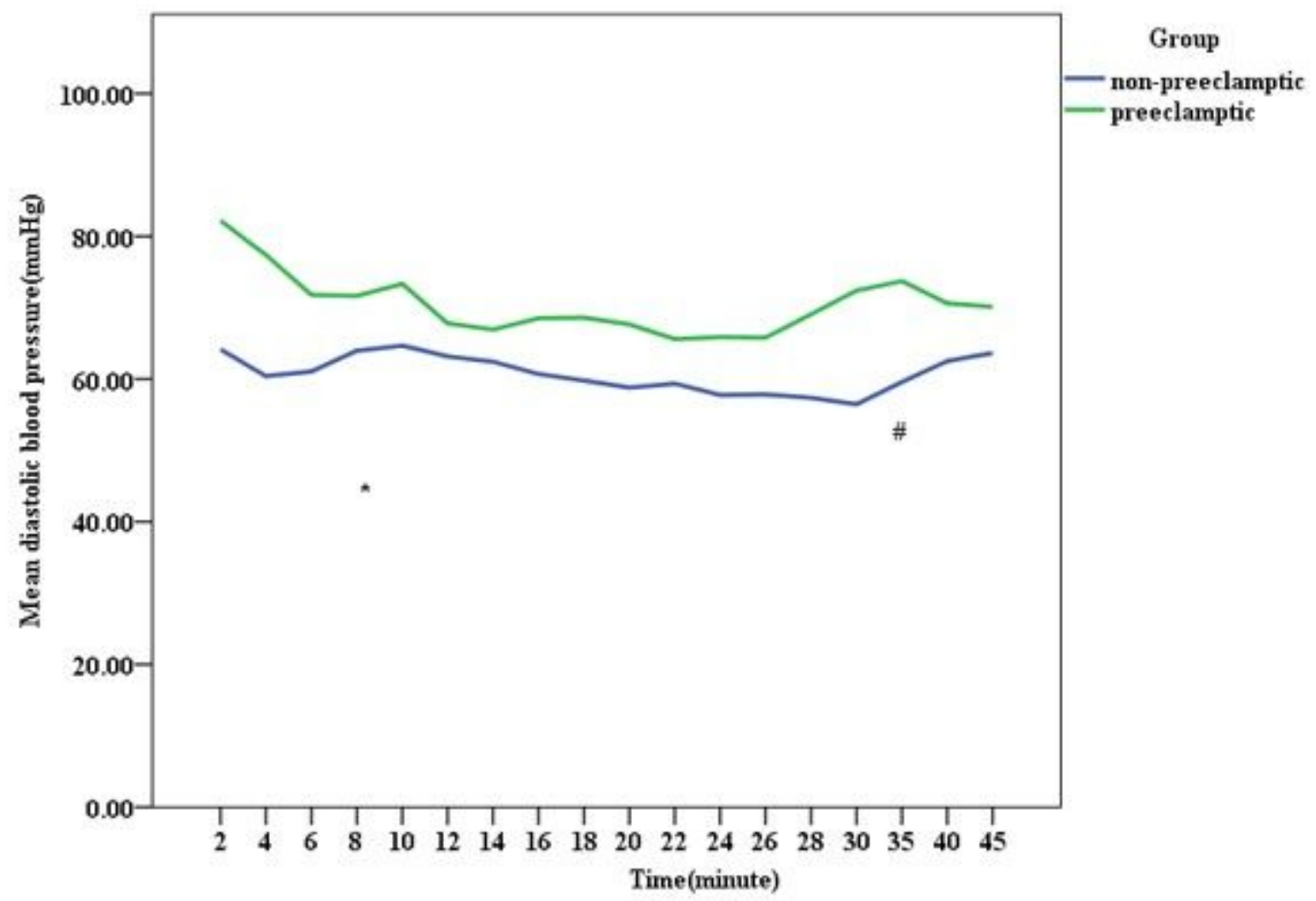

"time points at which there were insignificant difference in mean diastolic blood pressure between groups \# time points thereafter to the end of surgery there were insignificant difference in mean DBP between groups

\section{Figure 4}

Trends of diastolic blood pressure change following spinal anesthesia in non-preeclamptic and preeclamptic parturients, University of Gondar Northwest Ethiopia, May 2019(n=122). 